American Journal of Applied Sciences 4 (5): 284-293, 2007

ISSN 1546-9239

(C) 2007 Science Publications

\title{
Effects of Low Frequencies on Three Phase Induction Motor Performance Operating in Close Proximity to Rated Speed
}

\author{
Qazem Jaber, Qais Naman and Mahdi Shamaseen \\ Department of Mechatronics, Amman College for Engineering Technology, Al-Balqa University \\ PO Box 340535, Marka 11134, Amman
}

\begin{abstract}
Variable speed drives (VSD) are adhered to induction motors in most of the present industrial applications. And since the world has become more conscientious to energy saving, inverters established them selves in domestic buildings and industry. Square wave inverters generate dominant harmonics of the 5th, 7th, $11^{\text {th }}$ and $13^{\text {th }}$ order. Inverters based on PWM strategy produce much higher harmonic order depending on the frequency modulation ratio. The presence of any sub-synchronous harmonics (sub-harmonics) is usually unheeded probably to their ineffective magnitude. The work in this paper is to investigate the effects of low frequencies on the performance of induction motors running near rated peed. Low frequencies are superimposed on the motor by a second inverter cascaded with the main inverter. The results shown in this paper manifest the significant effects of subharmonics on the speed stability of induction motors. The results obtained also show that subharmonics can adversely affect the motor performance even if they are present with small amplitudes. This work is expected to lead to the notion of using low frequency injection in speed control of induction motors.
\end{abstract}

Key words: Three phase induction motor, harmonic torques, low, frequency, sub-harmonics, speed stability, inverters

\section{INTRODUCTION}

The calculation of harmonics torques in induction motors is carried out in similar manner to the fundamental taking into consideration the frequency of the harmonic order and its sequence with respect to the fundamental. Torque pulsation is estimated on different bases. Such estimation can be misleading due to nearness of the harmonic torques and torque pulsation frequencies and their interactive effects on the speed of induction motors.

The problems associated with sub-harmonics had not been investigated thoroughly in the same manner higher harmonics have been studied. Hence, with the increase of sub-harmonics injection in networks and the consequent voltage distortion, it is quite important now to study the effects of lower frequencies on induction motors performance.

The work in this paper is to investigate the effects of low order harmonics (sub-harmonics) in the range from 1 to $10 \mathrm{~Hz}$ on the performance of induction motor operating in proximity to rated speed. This paper explains the speed fluctuations that might result from sub-harmonics voltages present in the supply voltage.
The sources of sub-harmonic currents are diverse and swelling in power consumption like arc furnaces, cycloconverters...etc ${ }^{[1]}$.

Theoretically, it is possible to analyze the affects of cascaded ac sources of different frequencies and amplitudes by implementing the superposition method.

Figure 1 shows the power circuit diagram of the proposed system. The main inverter operates at both nominal voltage and frequency to achieve rated speed or speeds in proximity to rated speed. Such a configuration facilitates the possibility of any combinations of frequencies and voltage amplitudes. The cascading of inverters clarifies also how the lower frequency inverter can overcome the slow changes in speed. The frequency, amplitude and direction of rotation of the low frequency converter are chosen to counteract the speed variation in the induction motor. The complexity of such work is justified with the possibility of highly improved speed stability that could surpass the speed stability figures of dc motors ${ }^{[2]}$.

Type of Control: There are basically two types of control strategies for induction motors:

* Scalar control $(\mathrm{V} / \mathrm{f})$

Corresponding Author:

Qazem Jaber, Department of Mechatronics, Amman College for Engineering Technology, Al-Balqa University, PO Box 340535, Marka 11134, Amman 
Am. J. Applied Sci., 4 (5): 284-293, 2007

Table 1: Average speed of the motor at different low frequencies and different voltage while the main inverter is fixed at rated frequency $(50 \mathrm{~Hz})$ and rated voltage (380 V LL) for positive and negative sub-harmonic rotation

\begin{tabular}{|c|c|c|c|c|c|}
\hline \multicolumn{2}{|c|}{ Low frequency inverter } & \multirow{2}{*}{$\begin{array}{c}\text { Average speed } \\
\mathrm{rad} / \mathrm{sec}\end{array}$} & \multirow{2}{*}{$\begin{array}{c}\text { Speed fluctuation } \\
\mathrm{rad} / \mathrm{sec}\end{array}$} & \multirow{2}{*}{$\begin{array}{l}\text { Direction of } \\
\text { rotation }\end{array}$} & \multirow{2}{*}{$\begin{array}{c}\text { Speed ripple } \\
(\mathrm{Hz})\end{array}$} \\
\hline Frequency $\mathrm{Hz}$ & Voltage V (peak) & & & & \\
\hline 1 & 1 & 151.6 & 0.02 & $+\mathrm{ve}$ & 49 \\
\hline 5 & 1 & 151.7 & 0.03 & $+\mathrm{ve}$ & 45 \\
\hline 10 & 1 & 151.7 & 0.031 & $+\mathrm{ve}$ & 40 \\
\hline 1 & 5 & 151.6 & 0.1 & $+\mathrm{ve}$ & 49 \\
\hline 5 & 5 & 151.7 & 0.12 & $+\mathrm{ve}$ & 45 \\
\hline 10 & 5 & 151.8 & 0.14 & $+\mathrm{ve}$ & 40 \\
\hline 1 & 14.6 & 151.6 & 0.31 & $+\mathrm{ve}$ & 49 \\
\hline 5 & 13.9 & 151.7 & 0.3 & $+\mathrm{ve}$ & 45 \\
\hline 10 & 18.7 & 151.8 & 0.39 & $+\mathrm{ve}$ & 40 \\
\hline 1 & 14.7 & 5.4 & 3.4 & $+\mathrm{ve}$ & 49 \\
\hline 5 & 14 & 17.0 & 6.0 & $+\mathrm{ve}$ & 45 \\
\hline 10 & 18.8 & 36.8 & 4.5 & $+\mathrm{ve}$ & 40 \\
\hline 1 & 20 & 5.1 & 5.1 & $+\mathrm{ve}$ & 49 \\
\hline 5 & 20 & 4.6 & 4.6 & $+\mathrm{ve}$ & 45 \\
\hline 10 & 20 & 9.0 & 3.1 & $+\mathrm{ve}$ & 40 \\
\hline 1 & 5 & 151.6 & 0.196 & - ve & 51 \\
\hline 5 & 5 & 151.6 & 0.092 & - ve & 55 \\
\hline 10 & 5 & 151.6 & 0.082 & - ve & 60 \\
\hline
\end{tabular}

* Vector control (Field oriented control)

Both of the above control strategies can operate in speed control mode or torque control mode. Since most industrial applications use speed control only for their induction motors while torque control is seldom used, hence the work in this paper is abridged to speed control only. Scalar control is easier to implement and less costly compared to field oriented control so this paper might help the improvement of scalar control to surpass (FOC) in steady state conditions ${ }^{[3,4]}$. The system depicted in the power circuit diagram of Fig.1 comprises a main inverter that is delivering the full power to the motor at rated frequency and rated voltage or in proximity to these conditions and a low frequency inverter that furnishes the low frequency power. In order to disregard the effects of higher harmonic orders, the main inverter and the low frequency inverter are both assumed to be controlled by PWM scheme having high frequency modulation ratio. Thereby neglecting high frequency harmonic currents is justified.

The applied voltage to the motor can be written:

$$
V m=\hat{V}_{f}(\sin \omega t)+\hat{V}_{h}(\sin \omega t-\phi)
$$

The induction motor must respond to one frequency and run at a speed close to the synchronous speed corresponding to that prevailing frequency with small-superimposed oscillations caused by the low frequency injected to the induction motor. The present work assumes that the system is operating under normal conditions and the main inverter is supplying rated or in proximity to rated voltage and frequency. Hence it is the dominating power source while the low frequency inverter contributes to the fluctuations in speed. Field oriented control of the induction motor can reach figures for speed stability better than $0.1 \%$ according to literature reported by manufacturers. The work in this paper can be extended by introducing the low frequency inverter in such a manner to overcome low speed fluctuations and thereby speed stability can be pushed further down .The cascaded inverters can also benefit (VSD) using constant voltage to frequency ratio to eliminate torque pulsations and improve their overall performance which justifies the extra costs and complexity required by the new scheme $\mathrm{e}^{[5-9]}$.

Simulation parameters: In order to demonstrate the effectiveness of the proposed system, Simulation work has been carried out using MATLB/SIMULINK ${ }^{[10,11]}$.

Three phase squirrel cage induction motor having the following parameters has been tested at full torque. $\mathrm{HP}=15$, Voltage $=380 \mathrm{~V}(\mathrm{LL}), \mathrm{R}_{\mathrm{s}}=1.48 \Omega, \mathrm{X}_{\mathrm{ls}}=0.18$ $\Omega, \mathrm{R}_{\mathrm{r}}=0.31 \Omega, \mathrm{X}_{\mathrm{lr}}=0.18 \Omega, \mathrm{X}_{\mathrm{m}}=14.96 \Omega, \mathrm{N}=1471 \mathrm{rpm}$, $\mathrm{J}=0.834 \mathrm{~kg} / \mathrm{m}^{2}$. 
Main inverter: The main inverter is represented with three voltage sources having pure sinusoidal voltages and a frequency of $50 \mathrm{~Hz}$ and $380 \mathrm{~V}$ (LL).

Low frequency inverter: The low frequency inverter is represented with three voltage sources having pure sinusoidal voltages with variable frequency and variable voltage.

\section{RESULTS}

The main inverter was fixed at rated conditions while the frequency and voltage of the low frequency inverter was varied. Table 1 shows the average speed of the motor at different low frequencies and different voltage while the main inverter is fixed at rated frequency $(50 \mathrm{~Hz})$ and rated voltage $(380 \mathrm{~V} \mathrm{LL})$ for positive and negative sub-harmonic rotation.

Figure 2 shows the speed response of the motor at rated voltage, frequency and torque with no additional sub-harmonic. While Fig. 3 shows the same conditions with a sub-harmonic of $5 \mathrm{~Hz}$ and $5 \mathrm{~V}$ (peak) is a introduced. In spite of the small amplitude of subharmonic, the speed response of the motor began to show the effect of sluggishness.

Figure 4 shows the speed oscillation, with an additional sub-harmonic of $1 \mathrm{~Hz}$ and voltage amplitude of $5 \mathrm{~V}$ (peak) is inserted with the fundamental and with positive rotation. Figure 5 shows the system with $5 \mathrm{~Hz}$, $5 \mathrm{~V}$ (peak) and positive rotation is added while Fig. 6 shows the effects of adding $10 \mathrm{~Hz}, 5 \mathrm{~V}$ (peak) with positive rotation to the motor. Figure 7 shows the effects of $1 \mathrm{~Hz}, 5 \mathrm{~V}$ (peak) with negative rotation subharmonic on the motor.

The level of speed fluctuation increases almost linearly with the magnitude of the sub-harmonic voltage at different frequencies up to a certain limit where it attains a plateau. The motor starts to rotate at speeds that match the synchronous speeds of the subharmonic frequencies at voltages less than the expected values for all sub-harmonics. The effect of subharmonics with positive rotation worsens as the frequency is increased for the same voltage magnitude. While the effect improves for sub-harmonics with negative rotation as the frequency is increased.

Sub-harmonics effects: The frequency of the subharmonic, its amplitude and direction of rotation, all play roles on its effects on the performance of the induction motor. The outcome of the presence of a subharmonic can be summarized:

* The motor speed shows low frequency oscillation. Hence the motor loses high speed stability.

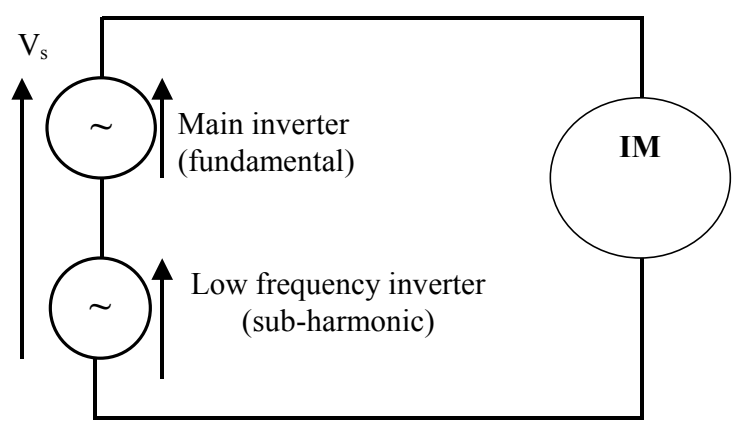

Fig.1: Power circuit diagram

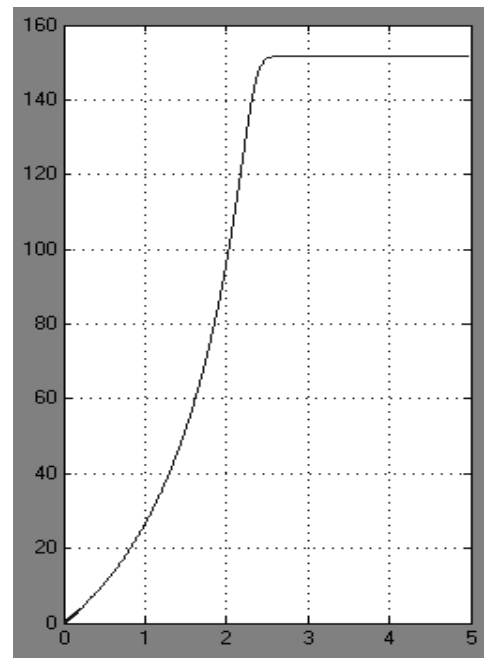

Fig. 2: Speed response of the motor at rated conditions

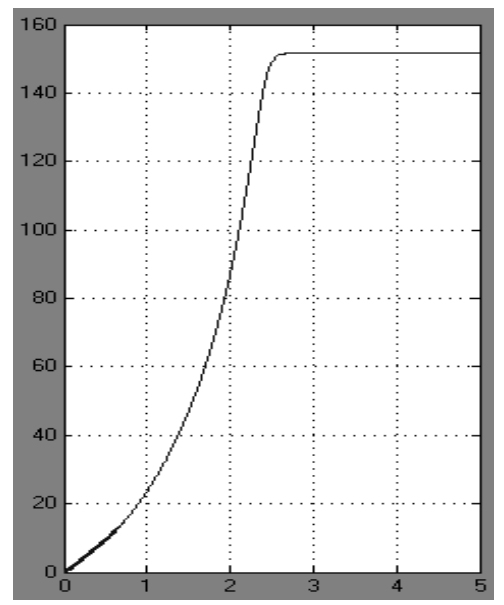

Fig. 3:Speed response of the motor with $1 \mathrm{~Hz}, 5 \mathrm{~V}$, positive rotation, sub-harmonic

* Direct calculation of the motor torque is not adequate unless the interaction of the air gap flux and rotor $\mathrm{mmf}$ of the different frequencies is introduced. 
Am. J. Applied Sci., 4 (5): 284-293, 2007

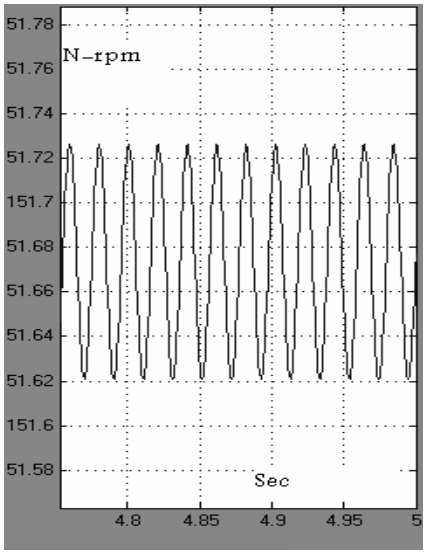

Fig. 4:Speed fluctuations with $1 \mathrm{~Hz}, 5 \mathrm{~V}$ (Peak), positive rotation sub-harmonic

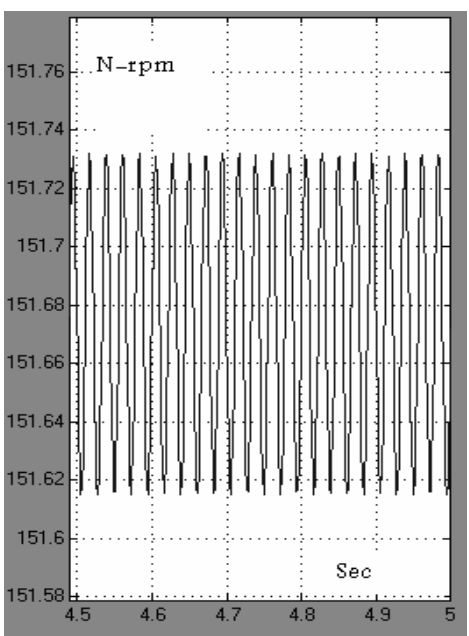

Fig. 5: Speed fluctuations with $5 \mathrm{~Hz}, 5 \mathrm{~V}$ (peak), positive rotation,. sub-harmonic

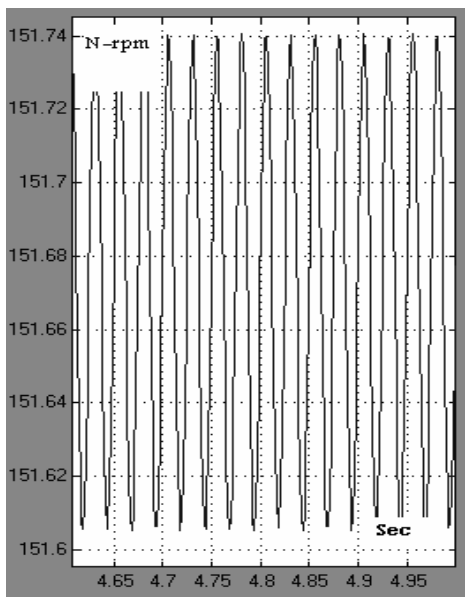

Fig. 6: Speed fluctuations with $10 \mathrm{~Hz}, 5 \mathrm{~V}$ (Peak), positive rotation sub-harmonic

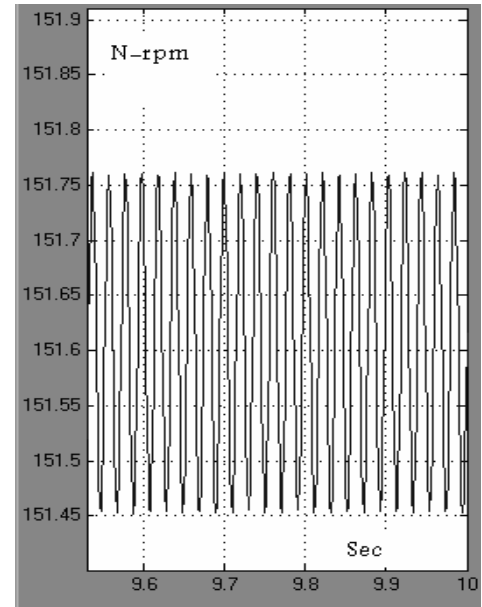

Fig. 7: Speed fluctuations with $1 \mathrm{~Hz}, 5 \mathrm{~V}$ (peak), negative rotation sub-harmonic

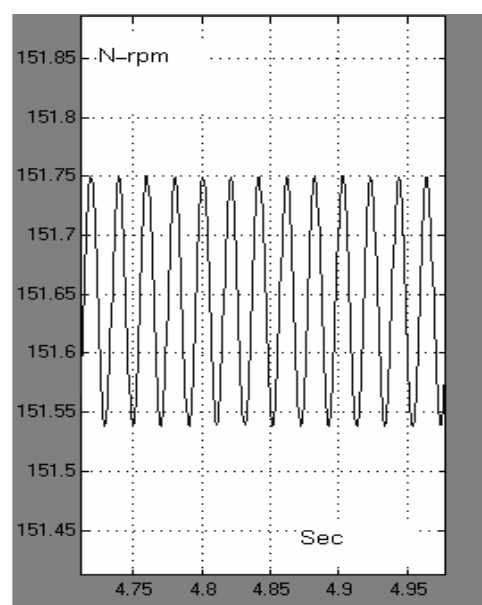

Fig. 8: Speed fluctuations with $1 \mathrm{~Hz}, 14.6 \mathrm{~V}$ (peak) positive rotation, sub-harmonic

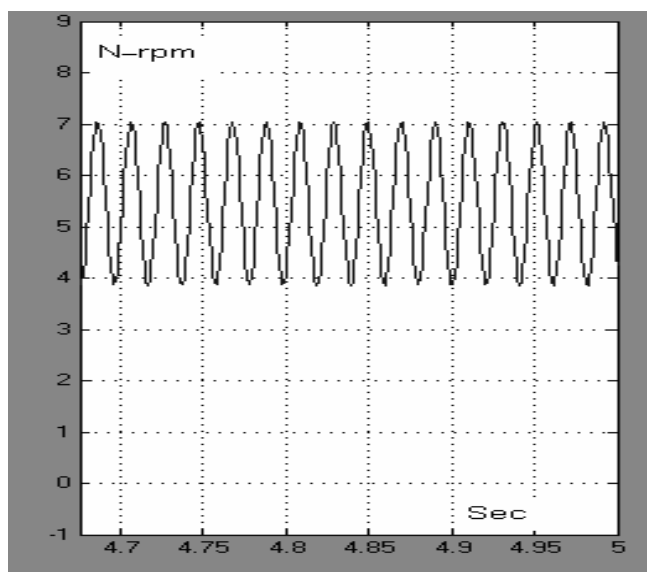

Fig. 9: Speed fluctuations with $1 \mathrm{~Hz}, 14.7 \mathrm{~V}$ (peak) positive rotation, sub-harmonic 
* The eventual effects of the direction of rotation of the sub-harmonic are directly affected by the interaction mentioned in 6-2.

* The dominance of stator resistance at lower frequencies adds another complexity to the calculations.

Speed fluctuations: The results obtained shows that the presence of sub-harmonics, even with small voltage amplitudes leads to low frequency oscillations. Every sub-harmonic has critical amplitude whereby the motor is compelled to rotate at a speed close to the synchronous speed of that particular sub-harmonic.

Figure 8 and 9 show the motor speed with $1 \mathrm{~Hz}$ sub-harmonic having voltages of 14.6 and $14.7 \mathrm{~V}$ (peak) respectively, rotating in positive sense with respect to the fundamental. The motor voltage limit for $1 \mathrm{~Hz}$ sub-harmonic falls between 14.6 and $14.7 \mathrm{~V}$ (peak). While for $5 \mathrm{~Hz}$ the voltage limit lies between 13.8 and $13.9 \mathrm{~V}$ (peak) and as shown in Fig. 10 and 11.

Figure 12 shows the speed of the induction motor vs. voltage for 1,5 and $10 \mathrm{~Hz}$. The voltage limit for 10 $\mathrm{Hz}$ is between 18.8 and $18.9 \mathrm{~V}$ (peak). Figure 13 depicts the speed fluctuations for 1,5 and $10 \mathrm{~Hz}$ while Fig. 14 shows these fluctuation including voltage limits. If the sub-harmonic has an opposite direction of rotation to the fundamental, then exceeding the voltage limit could cause a reversal in direction of rotation of the induction motor. The motor current is acceptable as long the speed is close to the synchronous speed at fundamental frequency of the induction motor. If the motor speed nears to the sub- harmonic synchronous speed, then the motor current becomes very excessive in both directions of rotations of the sub-harmonics with respect to the fundamental. Figure 15 and 16 show the motor current for normal operating condition and wit $14.7 \mathrm{~V}$ (peak) at a sub-harmonic frequency of $1 \mathrm{~Hz}$.

The magnetizing impedance $\mathrm{nX}_{\mathrm{m}}$ is assumed very high $\left(n X_{m} \text { approaches infinity for high values of } n\right)^{[12-}$ 15].

Torque calculation: The torque calculation for induction motor subjected to higher harmonics is based on the circuit configuration of Fig. 17. Higher harmonics that appear with square wave inverter and PWM strategy produce relatively small flux components compared to the fundament as a result of the high impedance of $\mathrm{nX}_{\mathrm{m}}$. Hence, the analysis is carried out on the basis of no magnetic circuit saturation.

Now for sub-harmonics the situation is completely different, the magnetization impedance approaches very small values for low frequencies in the range of $1 \mathrm{~Hz}$ and $5 \mathrm{~Hz}$ or even $10 \mathrm{~Hz}\left(\mathrm{nX}_{\mathrm{m}}\right.$ approaches zero for low

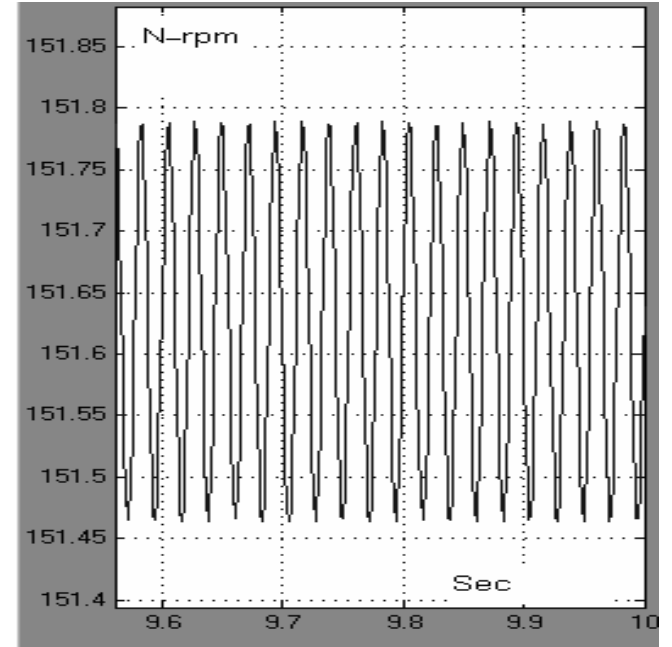

Fig. 10: Speed fluctuations with $5 \mathrm{~Hz}, 13.8 \mathrm{~V}$ (peak) positive rotation, sub-harmonic

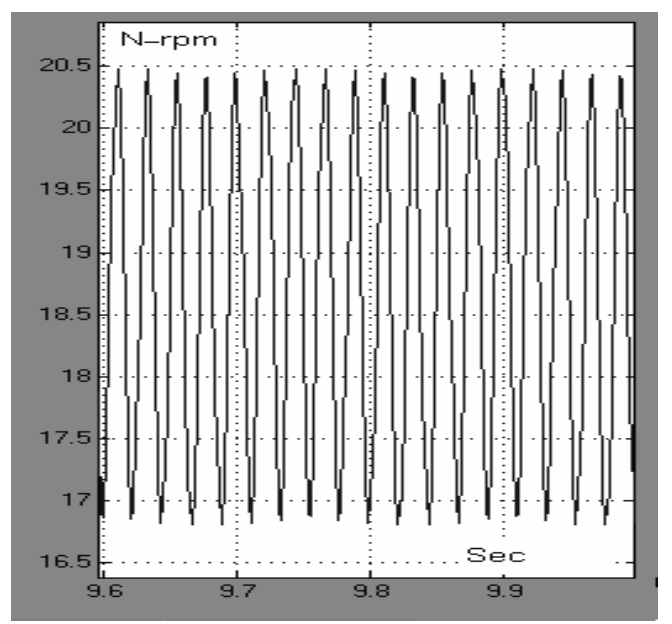

Fig. 11: Speed fluctuations with $5 \mathrm{~Hz}, 13.9 \mathrm{~V}$ (peak) positive rotation, sub-harmonic

frequency sub-harmonics). Figure 18 shows the per phase equivalent circuit of the induction motor for low frequency sub-harmonics.

For the fundamental frequency:

$\Psi_{f}=4.44 \hat{V} \sin \omega_{f} t$

And for any sub-harmonic

$\Psi_{h}=4.44 \widehat{V}_{h=a} \sin \left(\omega_{h} t-\theta_{h=a}\right)$

Hence the total flux is:

$\Psi_{t}=4.44 \widehat{V}_{f} \sin \omega_{f}+4.44 \widehat{V}_{h=1} \sin \left(\omega_{h=1} t-\theta_{h=1}\right)$

With $1 \mathrm{~Hz}$ sub-harmonic, the total air gap flux is expressed:

$\Psi_{t}=4.44 \widehat{V}_{f} \sin \omega_{f}+4.44 \widehat{V}_{h=1} \sin \left(\omega_{h=1} t-\theta_{h=1}\right)$ 


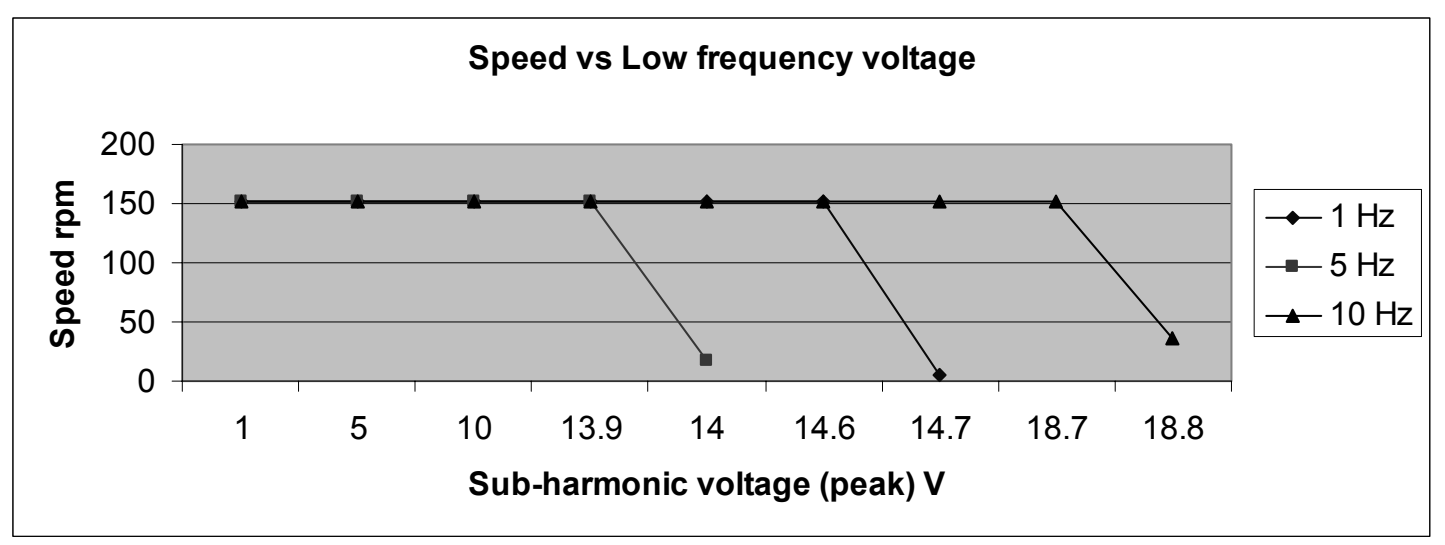

Fig. 12: Induction motor speed vs. sub-harmonic voltage (peak) for different frequencies

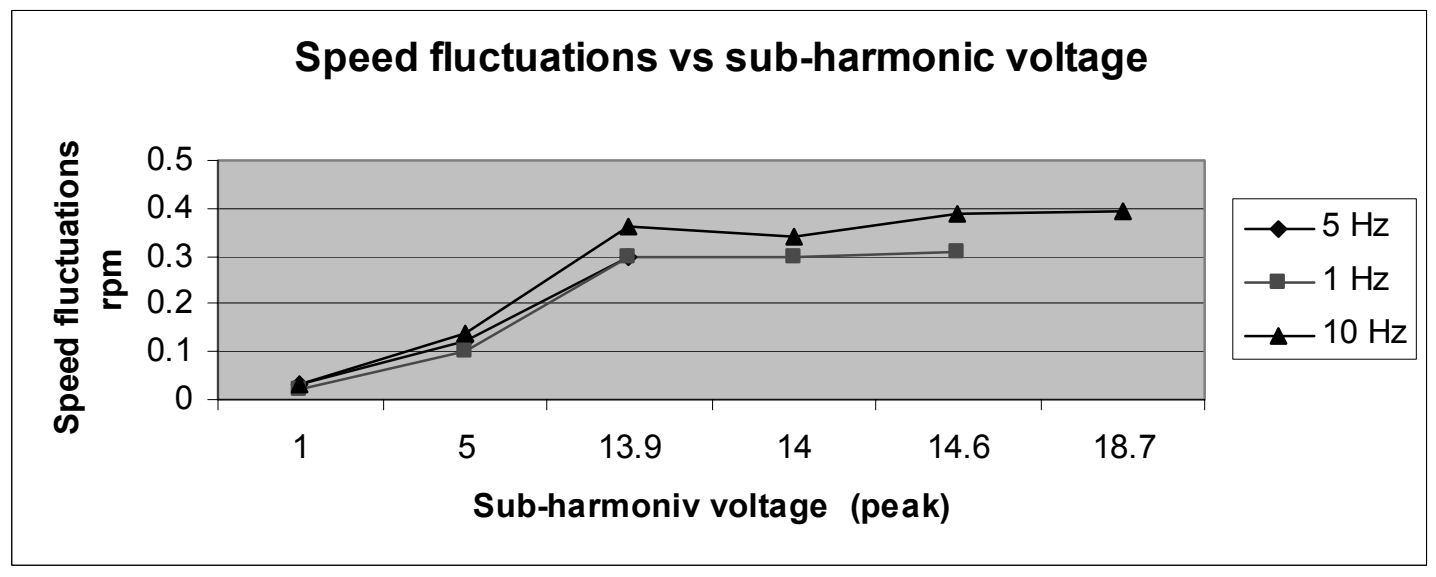

Fig. 13: Induction motor speed fluctuations vs. sub-harmonic voltage (peak) for different frequencies

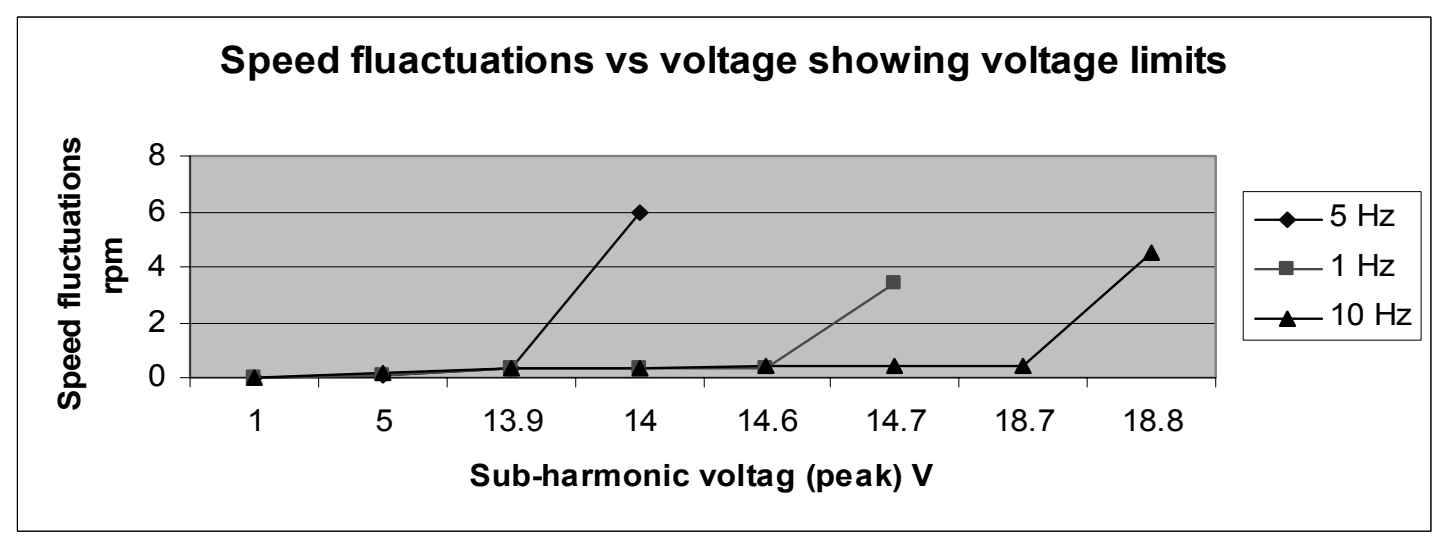

Fig. 14: Induction motor speed fluctuations vs. sub-harmonic voltage (peak) for different frequencies showing voltage limits

Assuming $\theta_{h=1}=0$

$\Psi_{t}=4.44 \widehat{V}_{f} \sin \omega_{f}+4.44 \widehat{V}_{h=1} \sin \left(\omega_{h=1} t\right)$
Equation 6 is applicable provided the magnetic circuit is not driven into saturation. 


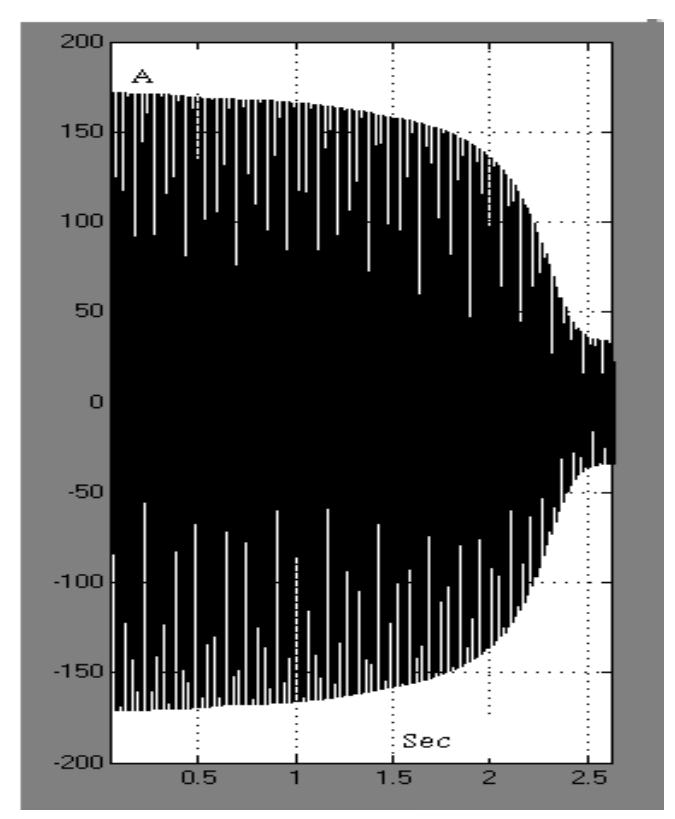

Fig. 15: Induction motor current at normal operating conditions (without sub-harmonics)

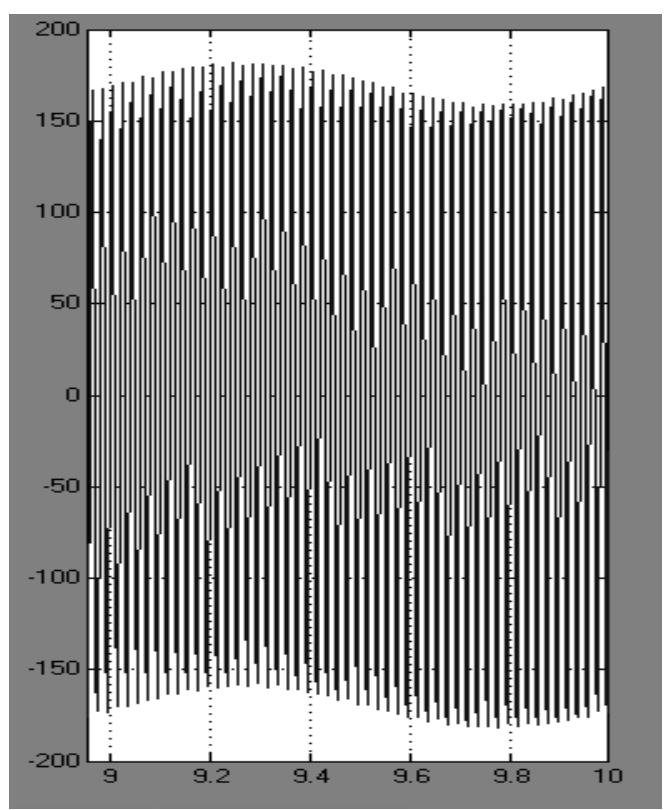

Fig. 16: Induction motor current with $1 \mathrm{~Hz}, 5 \mathrm{~V}$ (peak), positive rotation sub-harmonics

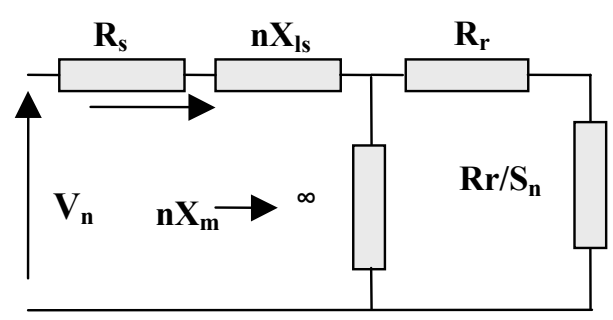

Fig. 17: Induction in motor per phase equivalent circuit for higher harmonics calculation

The magnetic circuit impedance has small values when subject to low frequency sub-harmonics. Thereby,

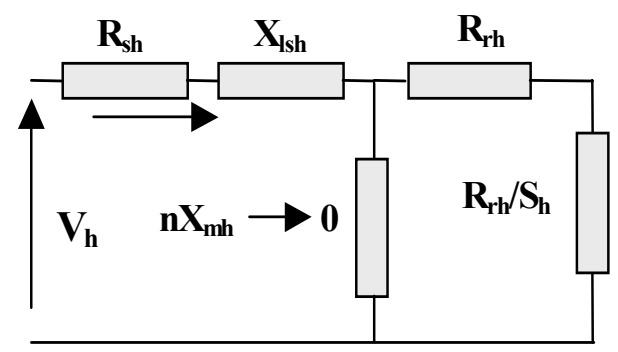

Fig. 18: Induction motor per phase equivalent circuit for sub-harmonics calculation

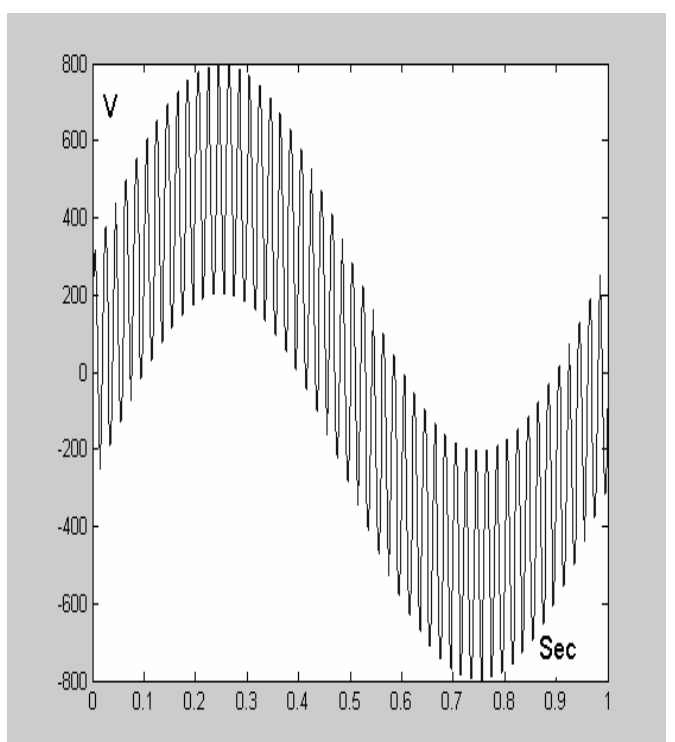

Fig. 19: Rated supply voltage with $1 \mathrm{~Hz}, 10 \mathrm{~V}$ (peak) multiplied by the frequency ratio 


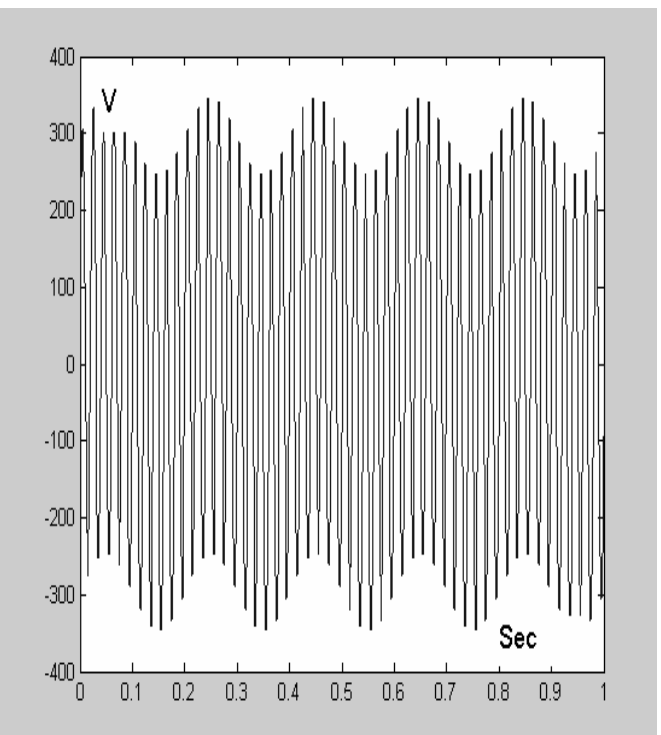

Fig. 20: Rated supply voltage with $5 \mathrm{~Hz}, 10 \mathrm{~V}$ (peak) multiplied by the frequency ratio

the low frequency flux generated by the sub-harmonic could be comparable to the fundamental flux depending on the amplitude and frequency of that sub-harmonic. As a result, the magnetic circuit could be deeply pushed into saturation.

The general torque equation is:

$$
T_{e}=3 \frac{P}{2} L_{m} I_{m} I_{a}
$$

And the breakdown torque:

$$
T_{e m}=\frac{3 P}{2}\left(\frac{V_{s}}{\omega_{e}}\right)^{2} \frac{\omega_{s l m} R_{r}}{R_{r}^{2}+\omega_{s L m}^{2} L_{l r}^{2}}
$$

The fundamental torque can be expressed:

$$
T_{e 1}=K \psi_{f r} I_{f r} \sin \delta
$$

And the pulsating torque due to the presence of $1 \mathrm{~Hz}$ sub-harmonic is:

$$
\begin{aligned}
& T_{e h=1}=K\left[\psi_{m f} I_{r h=1} \sin \left(\pi-0.98 \omega_{e} t\right)+\right. \\
& \left.\psi_{m h=1} I_{r f} \sin \left(\delta+0.98 \omega_{e} t\right)\right]
\end{aligned}
$$

And for $5 \mathrm{~Hz}$ sub-harmonic is:

$$
\begin{aligned}
& T_{e h=1}=K\left[\psi_{m f} I_{h=5} \sin \left(\pi-0.9 \omega_{e} t\right)+\right. \\
& \left.\psi_{m h=5} I_{r f} \sin \left(\delta+0.9 \omega_{e} t\right)\right]
\end{aligned}
$$

The above equations accuracy is deteriorated if the magnetic circuit is working into the saturation region of the hysteresis loop. Low frequency sub-harmonics could take the magnetic circuit well into saturation. This can be manifested by imposing a $10 \mathrm{~V}$ (peak) of 1 $\mathrm{Hz}$ sub-harmonic with the rated voltage and frequency supply of the induction motor (used for simulation). The effective supply voltage waveform is shown in Fig. 19. The effective voltage of $1 \mathrm{~Hz}$ sub-harmonic is based on assuming constant magnetizing impedance and multiplying the voltage by the corresponding frequency ratio and neglecting stator resistance voltage drop(stator leakage reactance is practically very small at $1 \mathrm{~Hz}$ ).

Figure 20 shows the effective supply voltage where $10 \mathrm{~V}, 5 \mathrm{~Hz}$ sub-harmonic is imposed on the motor rated voltage and frequency, the modulation effect is less severe with $5 \mathrm{~Hz}$ than that with $1 \mathrm{~Hz}$. Figure 21 shows the effect of the presence of $1 \mathrm{~Hz}, 1 \mathrm{~V}$ (peak) with the rated voltage.

The presence of low frequency sub-harmonics could have the following effects on the magnetic circuit:

* Magnetic circuit saturation

* Non-symmetrical B-H loops

The saturation of the magnetic circuit can have adverse effects on the performance of the induction motor. Magnetic saturation results from the high accumulatively flux of the sub-harmonic.

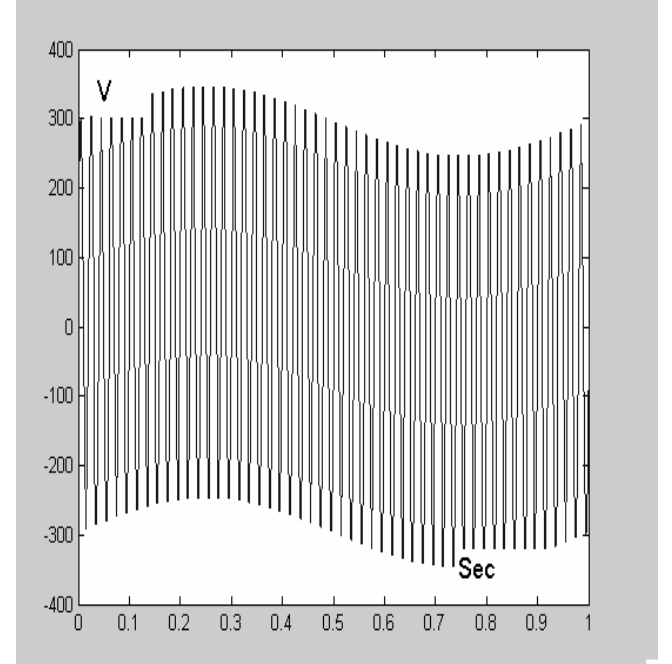

Fig. 21: Rated supply voltage with $1 \mathrm{~Hz}, 1 \mathrm{~V}$ (peak) multiplied by the frequency ratio

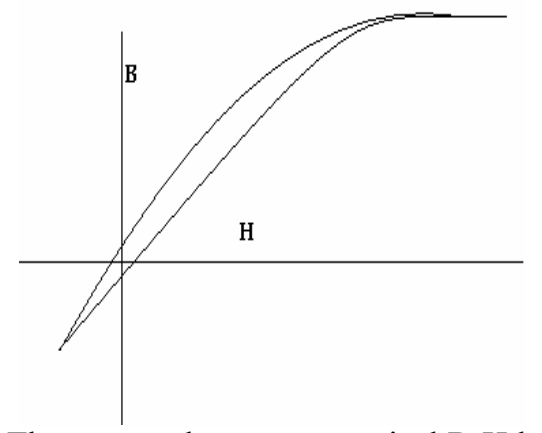

Fig. 22: The expected non-symmetrical B-H loop For 1 $\mathrm{Hz}$ sub-harmonic and rated $50 \mathrm{~Hz}$ supply voltage at $\mathrm{t}=250 \mathrm{~ms}$ 
The saturation of the magnetic circuit with nonsymmetrical B-H loop would result in torque oscillations and severe magnetizing current. Nonsymmetrical B-H loops are a result of the modulation effect of low frequency sub-harmonic during the positive and negative half cycles. For example, a subharmonic of $1 \mathrm{~Hz}$ and $10 \mathrm{~V}$ (peak) would result in nonsymmetry and different B-H loops for every $50 \mathrm{~Hz}$ cycle from $0-250 \mathrm{~ms}$ and from $500 \mathrm{~ms}$ up to $750 \mathrm{~ms}$. Fig. 22 show the expected B-H loops for $1 \mathrm{~Hz}$ sub harmonic imposed on the rated supply voltage of $50 \mathrm{~Hz}$ at the peak positive voltage of the $1 \mathrm{~Hz}$ sub-harmonic $(\mathrm{t}=250 \mathrm{~ms})$. The B-H loop could be driven much higher into saturation depending on the voltage amplitude of the $1 \mathrm{~Hz}$ sub-harmonic.

\section{CONCLUSION}

The present work tackles the problems associated with the presence of low frequency sub-harmonics and there effects on the performance of the induction motors operating in proximity to rated speed. Sub-harmonics have shown direct impact on speed stability even with small voltage magnitudes. This is due to the substantial reduction in stator leakage reactance at low frequencies. The induction motor speed has become closer to the synchronous speed of the applied subharmonic at a voltage lower than expected. This could be the result of the high saturation of the magnetic circuit caused by the present of the sub-harmonic flux. The saturation of the magnetic circuit leads to severe drop of the fundamental torque and consequently the motor speed. And as a result the motor current becomes excessive and can damage the motor if not well protected. The work in this paper has confirmed the undesirable effects on induction motors as a result of the increasingly sub-harmonic voltages in networks. Hence special attention must be given to the allowable voltage distortion level at sub-harmonic frequencies which is practically ignored now.

\section{Nomenclature}

f subscript denotes fundamental frequency of supply

$\mathrm{X}_{\mathrm{Isf}}$ Stator leakage reactance

$\mathrm{X}_{\mathrm{mf}}$ Magnetizing reactance

$\mathrm{R}_{\mathrm{sh}}$ Stator resistance

$\mathrm{S}_{\mathrm{f}}$ Slip

$\omega_{\mathrm{f}}$ Speed

$\mathrm{T}_{\mathrm{f}}$ Torque/fundamental frequency
$\Psi_{\mathrm{f}}$ Flux/fundamental frequency

$\mathrm{V}_{\mathrm{f}}$. Peak voltage

$\mathrm{R}_{\mathrm{rf}}$ Rotor resistance

$\mathrm{h}$ subscript denotes low frequency component (subharmonic) added to the system

a a has the value of the sub-

harmonic

$\mathrm{X}_{\mathrm{lsh}}$ Stator leakage reactance

$\mathrm{X}_{\mathrm{mh}}$ Magnetizing reactance

$\mathrm{R}_{\mathrm{sh}}$ Stator resistance

$\mathrm{S}_{\mathrm{h}}$ Slip

$\omega_{\mathrm{h}}$ Speed

$\mathrm{T}_{\mathrm{h}}$ Torque/sub-harmonic

$\Psi_{\mathrm{h}}$ Flux/sub-harmonic

$\mathrm{V}_{\mathrm{h}}$ Harmonic voltage (peak)

$\Theta$ Angle between harmonic

voltage and fundamental

$\mathrm{R}_{\mathrm{rh}}$ Rotor resistance

\section{REFERENCES}

1. IEEE Interharmonics Task Force, Cigrẻ 36.05/CIRED 2 CC02 Voltage Quality Working Group. Interharmonics in Power Systems, 12/1/97

2. Bose, B.K., 2002. Modern Power Electronics and Ac Drives. Prentice Hall PTR.

3. Holtz, J., 2001. Sensoreless Speed and Position Control of Induction Motors. 27th Ann. Conf. IEEE Industrial Electronics Society, IECON, Denver/Co, Nov.29-Dec. 2.

4. Holtz, J., 2001. Sensoreless Speed and Position Control of Induction Motors. 27th Ann. Conf. IEEE Industrial Electronics Society, IECON, Denver/ Co, Nov. 29-Dec. 2.

5. Singh, G.K., 2005. A research Survey of Induction Motor Operation with non-sinusoidal supply wave forms. Elsevier, Electric Power Systems Research, 75: 200-213.

6. Boglietti, A., M. Lazzari and M. Pastorelli, 2000. A simplified Method for the Iron Losses Prediction in Soft Magnetic Materials with Arbitrary Voltage Supply.

7. Narayanan, G. and V.T. Ranganathan, 2005. Analytical evaluation of Harmonic Distortion in PWM AC Drives Using the Notion of Stator flux Ripple. IEEE transactions on Power Electronics, 29: 2. 
8. Mthombeni, L.T., P. Pillay and N.A. Singampalli, 2003. Lamination Core Losses in Machines with PWM or Non- sinusoidal Excitation.

9. Boglietti, A., A. Cavagnino, T.L. Mthombeniand and P. Pillay, 2005. Comparison of Lamination Iron Losses Supplied by PWM Voltages: US and European Experiences.

10. Jaber, Q.M. and Q.A.H. Naman, 2005. High Speed Stabil6y of Induction Motors at Low Speeds Using V/f Control Method. J. Eng. Sci., Assiut University, 33: 1845-1853.

11. Henao, H., H. Razik and G.A. Capolino, 2005. Analytical Approach of the Stator Current Frequency Harmonics Computation for Detection of Induction Machine Rotor Faults. IEEE Trans. on Industry Applications, 41: 3 .
12. Mohan, U. and Robbins, 2003. Power Electronics Converter Applications and Design. John Wiley \&Sons, INC.

13. Policarpo, J. G de Abreu, S. De Sá and C.C. Prado, 2004. Harmonic Torques in Three-Phase Induction Motors Supplied by Non-Sinusoidal Voltages. 11th Intl. Conf. Harmonics and Quality of Power,

14. Pillary, P., E.J. Edendal and R.G. Harly, 1984. Torque and Speed Harmonic Analysis of PWM CSI-Fed Induction Motor Drive. The Trans. of the SA Institute of Electrical Engineers.

15. Rao, K.S.R. and M. Ramamoorly, 2003. Design Optimization of Inverter Fed 3-Phase Squirrel Cage Induction Motor. 